\title{
La Territorialización de las Políticas de Inclusión Social desde el punto de Vista de los Espacios Rurales Españoles: Comparativa Autonómica
}

\author{
The Territorialisation of Social Inclusion Policies from the Perspective of the \\ Spanish Rural Areas: Regional Comparative \\ Jaime Escribano-Pizarro \\ jaime.escribano@uv.es O http://orcid.org/0000-0002-2349-9997 \\ José Javier Serrano-Lara \\ j.javier.serrano@uv.es — http://orcid.org/0000-0003-0349-4176
}

Grupo de Investigación de Desarrollo Rural -Unidad de Desarrollo Rural y Evaluación de Políticas Públicas- UDERVAL (Instituto Interuniversitario de Desarrollo Local), Departamento de Geografía, Facultad de Geografía e Historia

Universidad de Valencia. Avda. Blasco Ibáñez, 28. 46010 Valencia

Diana Esmeralda Valero-López

diana.valero.perth@uhi.ac.uk (1) https://orcid.org/0000-0001-7565-770X

Centre for Mountain Studies. Perth College, University of the Highlands and Islands (Scotland).

Crieff Road, Perth, Scotland, PH1 2NX (UK)

\section{INFO ARTÍCULO}

Recibido: $17 / 05 / 2019$

Revisado: 23/11/2019

Aceptado: 29/11/2019

\section{PALABRAS CLAVE}

Políticas Sociales

Espacios Rurales

Pobreza

Exclusión Social

Inclusión Social

\section{KEYWORDS}

Social Policies

Rural Areas

Poverty

SocialExclusion

Social Inclusion

\section{RESUMEN}

En el artículo examinamos cómo se materializa la atención al medio rural en los planes de inclusión social españoles. Analizamos el marco estatal y autonómico clasificando las Comunidades Autónomas según su grado de ruralidad (OCDE). Así, establecemos si existe relación entre el carácter territorial de cada CCAA y el tipo de acciones inclusivas planteadas para los espacios rurales, y cuáles son los temas abordados. Los resultados evidencian que, al contrario de lo que cabría esperar, las CC.AA. predominantemente rurales no registran la mayor cantidad de actuaciones destinadas al medio rural, y que las temáticas sobre las que más se actúan atienden a la planificación y desarrollo territorial, la mejora formativa y educativa, y al apoyo a colectivos vulnerables. 


\section{INTRODUCCIÓN: JUSTIFICACIÓN, HIPÓTESIS Y OBJETIVOS DE TRABAJO1}

La exclusión social es un fenómeno complejo y multidimensional que hace referencia a las situaciones en las que un individuo y/o grupo de personas, debido a muy distintas variables sociales, políticas, geográficas, etc., tienen limitaciones para acceder a ciertos recursos y servicios, y además ejercer determinados derechos que para la gran mayoría de la población están disponibles. Como resultado se trata de una población, con frecuencia, con escasa o nula participación activa en la sociedad (Estivill, J., 2003). A través de las políticas de inclusión social se intenta dar respuesta a este hecho, aunque en realidad su resolución suele centrarse más en los espacios urbanos que en los rurales (Mathieu, N., 1997; Milbourne, P., 2010).

Sin embargo, esta relativa desatención no significa que la población del medio rural no experimente procesos exclusógenos. Al contrario, se trata de una sociedad mucho más vulnerable y afectada por los mismos debido a cuatro factores complementarios y, a menudo, simultáneos (i) de tipo laboral, por la falta de oportunidades de empleo, (ii) de carácter demográfico, por el éxodo de la población a las zonas urbanas, asociado a su vez a la falta de empleo y al envejecimiento de la población; (iii) relacionados con la falta de oferta educativa, especialmente en educación no obligatoria y, (iv) relativos a la accesibilidad a servicios básicos y a la falta de infoestructuras e infraestructuras adecuadas (Bertolini, P., et al., 2008; CES, 2018). Debido a estos factores, muchas zonas rurales experimentan serias complicaciones para salir del círculo vicioso de pobreza y exclusión resultante, en particular si en ellos residen además colectivos sociales que, por razones de género, origen, religión, etc., cuentan con vulnerabilidades intrínsecas (Milbourne, P., 2010; Bock, B., et al., 2015).

Por eso en las siguientes páginas decidimos examinar las políticas desarrolladas en el estado español en materia de inclusión social, con el objetivo de determinar cuáles son las principales actuaciones dirigidas al medio rural y en qué aspectos se centran, comprobando paralelamente su distribución a escala regional a través de una comparativa autonómica. Esta comparativa queda justificada al tomar en consideración que las políticas sociales en España, en particular aquellas destinadas a la pobreza y la exclusión social, son competencia de las Comunidades Autónomas (CCAA), y como ocurre en otros muchos aspectos sectoriales (ordenación territorial y urbanismo, turismo, etc.), el panorama de actuaciones desarrollado por las mismas se caracteriza por una evidente heterogeneidad (Valero, D. E., et al., 2016; CES, 2017).

Para ello, nos centramos en los Planes de Inclusión Social, en tanto en cuanto en ellos se recogen los enfoques, los objetivos y las actuaciones que se desean realizar y conseguir a nivel regional en el ámbito de la lucha contra la pobreza y la exclusión social. Debemos tener en cuenta que la política de inclusión social en España es el resultado de la aplicación de distintas estrategias desarrolladas sobre la materia a nivel europeo. De hecho, para los Estados Miembros (EEMM) de la Unión Europea la lucha contra la pobreza y la exclusión social ha sido, y es, uno de los principales objetivos de las políticas sociales, tal y como se recoge ya en la Carta Social Europea de 1961, uno de los primeros referentes en este ámbito temático (MEPSYD, 2009).

Es más, a través de la aparición y el desarrollo de distintos acuerdos en materia de lucha contra la pobreza, este concepto ha evolucionado, pasando de una acepción simplificada en la que se equiparaba a la falta de recursos, a una concepción más compleja y completa de carácter multidimensional. De este modo, en su lugar se habla de exclusión social, concepto vinculado tanto a la idea de proceso como de estado en el que convergen carencias en ámbitos diversos, como el formativo, el de salud, el del empleo, el de la vivienda o el de la participación en la vida pública (Boilineau, E. y Bonerandi-Richard, E., 2014). Sin embargo, no fue hasta el II Programa Europeo de Lucha contra la Pobreza de 1984, cuando se planteó por primera vez atender la pobreza con este enfoque multidimensional, convirtiéndose en la base para el desarrollo de las políticas sociales en Europa. De ahí que, a partir de la década de los noventa, los esfuerzos se concentraron en adoptar una perspectiva integradora de los aspectos relacionados con el crecimiento económico, el bienestar, la cohesión social, etc. La preocupación llegó a su máximo en la Cumbre de Lisboa (2000), cristalizándose en la

1. El presente trabajo aporta resultados preliminares de los proyectos financiados por el Ministerio de Ciencia e Innovación CSO2015-68215-R sobre Capital Social y Desarrollo Territorial en áreas rurales en España (cofinanciado por el FEDER), y de la Conselleria de Educación, Investigación, Cultura y Deporte de la Generalitat Valenciana GV/2017/081 sobre Redes sociales e innovación social: factores y estrategias de resiliencia frente a la pobreza y la exclusión social en los jóvenes y las mujeres del medio rural valenciano. Los autores quieren agradecer igualmente la colaboración de Dña. Helena van den Berg Sesma. 
constitución de la Agenda Social Europea. Desde entonces los EEMM están obligados a cumplir los objetivos de lucha contra la pobreza y la exclusión social a través de un Plan Nacional de Acción para la Inclusión Social (PNAIN) (MEPSYD, 2009).

El Estado Español elaboró su primer PNAIN, aprobado el 25 de mayo de 2001, para el período 2001-2003. Desde entonces se han redactado cinco planes más, siendo el último trabajado en el presente estudio y disponible a la finalización del mismo (septiembre de 2018), el diseñado y ejecutado para el período 20132016. Mediante tres ejes estratégicos (inclusión sociolaboral, garantía de prestaciones económicas y acceso a servicios básicos) este plan recoge los logros de todos los anteriores y se adapta a un contexto socioeconómico europeo cambiante. Estos tres ejes conforman el enfoque de la inclusión activa (IA), que es su pilar estructural y responde a la concepción multidimensional de la exclusión social, aplicando así la evolución conceptual del término que se produjo en Europa a lo largo de las décadas anteriores.

En general, todos los planes autonómicos de inclusión toman como modelo el PNAIN, pero disponen de cierto margen para establecer líneas de actuación propias. Sin embargo, y pese a que todas las CCAA cuenta con una diversidad territorial más o menos evidente (espacios urbanos y rurales, de montaña y/o litoral, etc.), nuestra hipótesis sugiere que es complicado encontrar en sus desarrollos actuaciones que den una respuesta específica a los distintos tipos de territorios que las conforman, particularmente, a los de carácter rural. Esta realidad resulta cuanto menos paradójica si tenemos en cuenta que, en más de una ocasión, ya se ha demostrado cómo los procesos de exclusión social afectan a más a la población de los espacios rurales que a la de los urbanos, especialmente en los países del sur y del este de Europa (Bernard, J., et al., 2019; Valero, D. E., et al., 2016).

Sin duda, el hecho de que cuando hablemos de exclusión social se haga desde razonamientos y estereotipos urbanos, en donde los fenómenos en cuestión afectan a unos colectivos concretos espacialmente bien delimitados, frente a la realidad rural, en la que los individuos y/o familias en situación o riesgo de exclusión social aparecen camuflados por la conformidad social y cultural, y dispersos en el espacio de acuerdo al modelo de poblamiento típico, contribuye en gran parte a esta perspectiva de actuación diferenciada (Escribano, J. y Valero, D. E., 2018). Sin embargo, en ningún caso esto es excusa para que los territorios rurales no reciban la misma atención o prioridad que la dirigida a las ciudades. El aislamiento geográfico, pero sobre todo la falta de conexiones socioeconómicas y políticas ("conectividad") (Bock, B., 2016) de muchos espacios rurales, provoca en consecuencia que sus habitantes sufran una mayor vulnerabilidad y exposición a los procesos de exclusión, y tengan claras y permanentes dificultades para darles respuesta (Furuseth, O., 1998; Farrell, G., et al., 2000; Escribano, J., et al., 2019).

En consecuencia, nuestros objetivos son, por un lado, analizar las políticas de inclusión social autonómicas disponibles en septiembre de 2018, para determinar la atención que en ellas reciben los territorios rurales. Y, por otro, determinar si las CCAA predominantemente rurales (de acuerdo con el criterio de la OCDE para la delimitación de la ruralidad) son las que más acciones presentan de cara a favorecer de la inclusión social de dichos territorios, tal y como cabría esperar.

\section{METODOLOGÍA Y FUENTES DE INFORMACIÓN}

Para lograr nuestros objetivos hemos identificado los planes existentes en materia de inclusión social, comenzando por el PNAIN 2013-2016 y pasando seguidamente a examinar los vigentes a nivel autonómico (Cuadro 1). El análisis realizado en cada uno de los trece planes activos localizados (a fecha de septiembre de 2018) se ha centrado en las medidas que, recogidas en las líneas estratégicas de los mismos, se ajustan exclusivamente al medio rural. Con frecuencia, estas líneas estratégicas se inspiran en el enfoque de la IA establecido por la UE, y que recoge el propio PNAIN, por lo que muchos de los planes autonómicos también toman como base dicho enfoque para desarrollar sus medidas. De este modo, la prevención y la intervención aparecen como estrategias claves para favorecer una política más eficaz. Como resultado, en la práctica la IA se configura en torno a tres ejes estratégicos a través de los que ofrecer una primera respuesta política en esta materia. Los tres ejes estratégicos se centran en (i) impulsar la inclusión sociolaboral a través del empleo, ofreciendo especial atención a las familias con hijos menores, (ii) garantizar unas prestaciones eco- 
nómicas de apoyo a los colectivos e individuos más vulnerables y, (iii) garantizar la prestación de servicios básicos (servicios sociales, educación, sanidad, vivienda y sociedad de la información). Para cada uno de estos objetivos estratégicos, se establecen una serie de objetivos operativos a partir de los cuales se desarrollan unas actuaciones concretas de tipo temático (por ejemplo, empleo, vivienda, etc.).

Para encontrar las medidas destinadas explícitamente al medio rural en este marco operativo, se optó por un análisis de contenidos. Todo análisis de contenidos se divide en dos fases que se complementan: primero, el análisis conceptual, que consiste en detectar conceptos o términos para su posterior análisis, y segundo, el análisis relacional, con el que se pretende establecer las relaciones que existen entre los conceptos analizados en el paso anterior (Esparcia, J., 2010). Nuestro análisis de contenidos partió de una búsqueda de palabras y raíces léxicas relacionadas con el concepto de rural e ideas asociadas a dicha realidad geográfica (pueblo, campo, agricultura, despoblación, éxodo, rural, etc.) en todos los planes seleccionados.

Una vez realizado el estudio individual de cada plan, efectuamos el análisis comparativo. En este punto debemos tener en cuenta que el propio ámbito de actuación espacial de los planes analizados, siempre nivel autonómico, nos marca la escala de trabajo empleada en la investigación (NUTS2), por otro lado, habitual en las comparaciones sobre exclusión social y pobreza a nivel europeo (Bernard, J., et al., 2019). Para ello, clasificamos las CCAA desde un punto de vista general como predominantemente urbanas o rurales. En cualquier caso, entendemos que esta dicotomía oculta realidades más complejas, puesto que no todo el territorio de una CCAA es siempre urbano o rural, sino que en su interior encontramos una red de nodos que pivotan entre ambas opciones, alcanzado en algunos casos una mayor presencia aquellos con rasgos urbanos, mientras que en otros prevalecen los de carácter rural (Camarero, L., 1993).

Cuadro 1. Planes de inclusión social autonómicos.

\begin{tabular}{|c|c|c|}
\hline CCAA & Período & Denominación \\
\hline Andalucía & 2014-2020 & $\begin{array}{l}\text { Estrategia Regional Andaluza para la Cohesión e Inclusión Social. Intervención } \\
\text { en zonas desfavorecidas }\end{array}$ \\
\hline Aragón & 2014-2020 & Estrategia del Programa Operativo del Fondo Social Europeo de Aragón \\
\hline Asturias & 2015-2017 & Plan Autonómico de Inclusión Social \\
\hline Cantabria & 2014-2017 & I Plan de Acción para la Inclusión en Cantabria \\
\hline Castilla y León & 2017-2021 & Plan Estratégico de Servicios Sociales \\
\hline Castilla-La Mancha & $2017-2020$ & Estrategia contra la Pobreza y Desigualdad Social en Castilla-La Mancha \\
\hline Cataluña & 2015-2016 & Pla d’acció per a la lluita contra la pobresa i per a la inclusió social a Catalunya \\
\hline Com. de Madrid & 2016-2021 & Estrategia de Inclusión Social de la Comunidad de Madrid \\
\hline Com. Valenciana & 2017-2022 & Plan Valenciano de Inclusión y Cohesión Social \\
\hline Extremadura & $2014-2020$ & Estrategia del Programa Operativo del Fondo Social Europeo de Extremadura \\
\hline Galicia & $2014-2020$ & Estrategia de Inclusión Social de Galicia \\
\hline Navarra & $2018-2021$ & Plan Estratégico de Inclusión de Navarra \\
\hline País Vasco & $2017-2021$ & IV Plan Vasco de Inclusión. Euskadi, Territorio Inclusivo \\
\hline
\end{tabular}

Fuente: Elaboración propia a partir de los planes de inclusión analizados.

Es cierto que las posibilidades de delimitación y definición de los territorios urbanos o rurales son múltiples y numerosas (Paniagua, A. y Hoggart, K., 2002), aunque debido a la obligación de trabajar a escala autonómica, emplearemos por su facilidad para obtener los datos y operar con ellos, la categorización que del espacio rural establece la OCDE en 1994. En ella se caracteriza un espacio concreto como urbano cuando se 
sobrepasan los 150 habitantes por kilómetro cuadrado, mientras que si la densidad demográfica es inferior a esta misma cifra nos encontramos ante un espacio considerado como rural (Goerlich, F. J., et al., 2016). Para realizar este cálculo empleamos los datos demográficos del Padrón Municipal de 2017, obteniendo como CCAA predominantemente urbanas las correspondientes a los archipiélagos Balear y Canario, País Vasco, la Comunidad de Madrid, Cataluña y la Comunidad Valenciana, mientras que las once autonomías restantes resultan tipificadas como regiones predominantemente rurales.

\section{RESULTADOS Y DISCUSIÓN}

Seguidamente sintetizamos el estudio de los catorce planes analizados (el nacional y los trece autonómicos), destacamos las actuaciones y medidas principales dirigidas al medio rural, e incorporamos los resultados que resultan de dichos análisis y la comparativa autonómica resultante.

\subsection{Plan nacional de acción para la inclusión social 2013-2016}

La Cumbre de Niza de 2001 marca el inicio de la planificación de la inclusión social en España. Desde entonces y hasta 2010 se sucedieron en España cinco planes nacionales de inclusión social de forma ininterrumpida: el I PNAIN 2001-2003, el II PNAIN 2003-2005, el III PNAIN 2005-2006, el IV PNAIN 2006-2008, y el V PNAIN 2008-2010. Todos ellos mantenían unas líneas de actuación similares para el medio rural referidas básicamente al establecimiento de servicios, infraestructuras e inversiones tecnológicas y digitales, la mejora de la calidad de vida infantil, la recuperación de núcleos rurales a través de actuaciones sobre la vivienda, y el establecimiento del Sistema para la Autonomía y Atención a la Dependencia.

Ahora bien, la irrupción de la crisis económica supuso un cambio en la concepción de estas políticas, que estuvieron sin programación específica desde 2010 hasta la llegada del PNAIN 2013-2016. Con él se materializó un cambio significativo en los contenidos específicos para el medio rural, ya que a partir de ahora las actuaciones dirigidas a este se organizan alrededor de medidas de inclusión sociolaboral, con programas formativos y acciones dirigidas a mejorar la integración laboral de inmigrantes y mujeres en el medio rural. Es decir, el PNAIN 2013-2016 solo coincide con sus predecesores en su apoyo explícito a la incorporación de las áreas rurales a la sociedad de la información, presentando, por el contrario, un conjunto de actuaciones y destinatarios relativamente más amplio y diverso (Cuadro 2 ).

Pese a la mayor sensibilidad por el medio rural del PNAIN 2013-2016, las actuaciones concretas destinadas a este siguen siendo limitadas en comparación a las dirigidas explícitamente al ámbito urbano. Así, solo nueve están orientadas directamente a los espacios rurales y/o en dificultad, de un total de 240 previstas (menos de un 4\%). Este resultado refleja sin duda la relativa escasa capacidad que los PNAIN tienen para aplicar un enfoque territorial en su organización, sobre todo, desde el punto de vista de la ruralidad. Sin embargo, el análisis realizado evidencia de igual modo que el medio urbano tampoco es abordado explícitamente en el plan, por lo que se puede afirmar que el enfoque que predomina es un tanto genérico y que, en principio, son las administraciones autonómicas las que deben desarrollar una respuesta personalizada según las características de sus territorios.

Al respecto, los sucesivos informes de la "Asociación Estatal de Directoras y Gerentes de Servicios Sociales" señalan importantes diferencias autonómicas en un contexto de deterioro general de los mismos en todo el país. Este resultado era ya anunciado en la investigación realizada por la Fundación Fomento de Estudios Sociales y de Sociología Aplicada (FOESSA) sobre exclusión y desarrollo en 2014, al apuntarse que las desigualdades entre autonomías derivaban de la "fragmentación de las responsabilidades de provisión" y de la "carencia de regulación jurídica capaz de asegurar el acceso igualitario a la oferta" (Aguilar, M., et al., 2014, 340). Todo ello, además, agravado por las diferencias inherentes a la realidad interna de cada Comunidad Autónoma, como respuesta al desarrollo histórico de los Servicios Sociales como competencias municipales. De este modo, obtenemos una política social fragmentada en disposiciones estatales, autonómicas y locales, en la que la tradicional falta de cooperación en la provisión efectiva de los servicios sociales en el medio 
Cuadro 2. Actuaciones destinadas explícitamente al medio rural en el PNAIN 2013-2016.

\begin{tabular}{|c|c|c|c|c|}
\hline Eje & Objetivo estratégico & Objetivo operativo & Actuación & Tema \\
\hline \multirow{8}{*}{1} & \multirow{5}{*}{1} & \multirow{4}{*}{1} & 2 & Empleo \\
\hline & & & 12 & Mujer / Género \\
\hline & & & $18 \mathrm{~F}$ & Inmigración/Refugiados \\
\hline & & & 21 & Educación / formación \\
\hline & & 5 & 39 & TIC \\
\hline & \multirow{3}{*}{3} & 17 & 138 & Acceso a servicios y prestaciones \\
\hline & & 22 & 161 & Diagnóstico territorial \\
\hline & & 23 & 167 & TIC \\
\hline 2 & \multicolumn{2}{|c|}{$\mathrm{B}$} & 186 & Discapacidad \\
\hline
\end{tabular}

Fuente: MSSSI, 2014.

rural (Cabero, V., et al., 2010), complica la labor de los profesionales encargados de los mismos, obligándoles a suplir tales problemas únicamente con su buen hacer y (pre)disposición (Escribano, J., 2012).

\subsection{Los planes autonómicos}

No todas la CCAA se encuentran en igual situación en cuanto al desarrollo de planes o estrategias con las que hacer frente a los procesos de exclusión social, ya que mientras la mayoría dispone de planificación vigente (o recientemente expirada, como el caso de Asturias, Cantabria y Cataluña), algunas Ilevan varios años sin actualizarla (como ocurre con La Rioja ${ }^{2}$ y las Islas Canarias ${ }^{3}$ ), y otras nunca han llegado a desarrollar plan alguno (caso de Murcia y de las Islas Baleares) (MEPSYD, 2009). Entre las CCAA que sí cuentan con un documento en uso encontramos Aragón, Asturias, Cantabria, Castilla y León, Castilla-La Mancha, Comunidad Valenciana, Extremadura, Galicia, Navarra y País Vasco. A ellas se suman Andalucía, Cataluña y Comunidad de Madrid, si bien estas restan al margen porque en ninguno de los planes correspondientes se identifican objetivos o actuaciones destinadas específicamente al medio rural. Es decir, se trata de una planificación en donde, como también ocurre en los examinados, se recogen medidas para las personas y/o grupos sociales afectados por la pobreza y la exclusión social que pueden ser aplicadas a cualquier tipo de espacio y/o sociedad. Pero, como señalábamos en nuestro planteamiento inicial, esto no garantiza la resolución de los problemas relativos a los procesos de exclusión social que experimentan concretamente los territorios rurales.

\subsubsection{Aragón}

El planteamiento de esta autonomía para el período 2014-2020 con el que hacer frente a la exclusión social, descansa en la elaboración de una estrategia basada en el Programa Operativo del Fondo Social Europeo (FSE). Esta se organiza en tres ejes estratégicos que, acorde con el enfoque de IA, recogen cuestiones relacionadas con el mercado de trabajo y las políticas activas de empleo, la inclusión social y la educación. Cada uno de estos ejes se concreta en un objetivo temático, a su vez es desglosado en unas prioridades de inversión que dan lugar a determinados objetivos específicos con distintas líneas de actuación. Estas son las únicas en 
las que se materializa explícitamente el interés por el medio rural, si bien no todas las actuaciones recogidas en la estrategia aragonesa van dirigidas a este. Las que sí que lo hacen se centran sobre todo en el segundo eje, dirigido en particular hacia la inclusión social (Cuadro 3).

Cuadro 3. Actuaciones destinadas a las zonas rurales en Estrategia del Programa Operativo del FSE de Aragón (2014-2020).

\begin{tabular}{|c|c|c|c|c|c|}
\hline Eje estratégico & Obj. temático & $\begin{array}{l}\text { Prioridad de } \\
\text { inversión }\end{array}$ & Obj. específico & Actuación & Tema \\
\hline 1 & 8 & 1 & 2 & 1 & Empleo \\
\hline \multirow{5}{*}{2} & \multirow{5}{*}{9} & \multirow{2}{*}{1} & \multirow{2}{*}{1} & 3 & Discapacidad \\
\hline & & & & 4 & Inmigración \\
\hline & & \multirow{2}{*}{4} & \multirow{2}{*}{1} & 2 & Transporte \\
\hline & & & & 3 & Planificación integral \\
\hline & & 6 & 1 & 1 & LEADER \\
\hline
\end{tabular}

Fuente: Gobierno de Aragón, 2014.

Del conjunto de acciones que se recogen en el segundo eje destacan, sobre todo, las orientadas hacia el desarrollo local participativo (o también conocido como enfoque LEADER), que legitima y capacita a la propia sociedad rural para buscar las mejores soluciones a sus problemas y necesidades. Este planteamiento supera el habitual carácter preventivo y asistencial de muchas de las medidas habituales para afrontar la vulnerabilidad de los colectivos sociales con riesgo de exclusión social, al promover el desarrollo también de actuaciones positivas de cara a la inclusión.

\subsubsection{Asturias}

El II Plan de Inclusión Social del Principado de Asturias (2015-2017) se enmarca en el contexto normativo europeo de la IA y de los distintos PNAIN, y se presenta como un plan que pretende superar las prácticas descoordinadas, inconexas y cortoplacistas habituales en el ámbito de la exclusión social, para ajustarse mejor a la complejidad que conlleva la multidimensionalidad de dicho concepto.

El plan asturiano aspira a responder de forma transversal a las necesidades y demandas relacionadas con la inclusión social a través de tres ejes estratégicos, cada uno de los cuales se divide en varios objetivos operativos, medidas y, finalmente, actuaciones. Su desarrollo permite abordar cuestiones relacionadas con la universalización de los servicios sociales y rentas básicas, planteamiento lógico si tenemos en cuenta que estamos ante un plan que se apoya en la Ley 1/2003 de Servicios Sociales del Principado de Asturias. Ahora bien, las acciones identificadas con una clara orientación hacia el medio rural se centran en los proyectos locales, la educación, la vivienda y las TIC, siendo relativamente escasa la importancia concedida a colectivos concretos (Cuadro 4).

\subsubsection{Cantabria}

Al igual que en el resto de CCAA, el I Plan de Acción para la Inclusión Social en Cantabria 2014-2017 se desarrolla acorde el principio de IA que aparece recogido en el PNAIN 2013-2016. Sin embargo, a diferencia de este son cuatro y no tres los ejes estratégicos que estructuran el plan. De ellos, derivan un conjunto de objetivos operativos y actuaciones que transcienden el ámbito de los servicios sociales, para extenderse a todas las áreas de gestión del gobierno cántabro capaces de aportar en la lucha contra la exclusión social o el riesgo de que esta se produzca. Este es el caso de, por ejemplo, el ámbito sanitario, cuya planificación sectorial plantea medidas que resultan oportunas para el logro de los objetivos del plan de inclusión cántabro. Se reconoce así que los planteamientos realizados exclusivamente por los servicios sociales son insuficientes para lograr la inclusión social de personas en riesgo de exclusión. 
Cuadro 4. Actuaciones destinadas a las zonas rurales en el Plan Autonómico de Inclusión Social del Principado de Asturias (2015-2017).

\begin{tabular}{|c|c|c|c|l|}
\hline Eje estratégico & Objetivo operativo & Medida & Actuación & \multicolumn{1}{|c|}{ Tema } \\
\hline \multirow{2}{*}{2} & 2 & 2.3 & 1 & Proyectos locales \\
\cline { 2 - 5 } & 3 & 3.3 & 13 & Inclusión social \\
\hline \multirow{3}{*}{3} & 5 & 5.3 & 19 & Mayores \\
\cline { 2 - 5 } & 6 & 6.2 & 2 & Vivienda \\
\hline & 8 & 8.1 & 8 & TIC \\
\hline
\end{tabular}

Fuente: Principado de Asturias (2015).

Del total de 263 actuaciones que contempla el plan cántabro para el logro de la inclusión, tan solo diez están dirigidas explícitamente al medio rural (Cuadro 5). De ellas, el empleo es la temática más frecuente con un total de cuatro medidas, evidenciando su papel fundamental como respuesta a la problemática de la exclusión social. En segundo lugar, destacan las acciones dirigidas a los colectivos vulnerables, con dos medidas, con las que se busca mejorar la situación de esta población especialmente en temas de igualdad social y laboral. Por último, encontramos un conjunto de actuaciones diversas destinadas al ámbito social, al sanitario, a la planificación local y a la vivienda, con el objetivo de que los individuos y familias en situación o riesgo de exclusión puedan mejorar su calidad de vida sin tener que abandonar su entorno residencial.

Cuadro 5. Actuaciones destinadas a las zonas rurales en el Plan de Acción para la Inclusión de Cantabria (2014-2017).

\begin{tabular}{|c|c|c|c|}
\hline Eje estratégico & Objetivo operativo & Actuación & Tema \\
\hline \multirow{5}{*}{1} & 1 & 4 & Empleo \\
\hline & 1 & 12 & Empleo \\
\hline & \multirow{2}{*}{3} & 26 & Planificación integral \\
\hline & & 27 & Empleo \\
\hline & 4 & 31 & Empleo \\
\hline 3 & 11 & 77 & Social \\
\hline \multirow{4}{*}{4} & 32 & 183 & Sanidad \\
\hline & \multirow{2}{*}{35} & 209 & Vivienda \\
\hline & & 212 & Discapacidad \\
\hline & 43 & 244 & Mujer / Género \\
\hline
\end{tabular}

Fuente: Gobierno de Cantabria, 2014.

\subsubsection{Castilla y León}

Castilla y León no dispone de un plan de acción específico para la inclusión social como tal, sino que cuenta en su lugar con un Plan Estratégico de Servicios Sociales (2017-2021). Luego, la planificación correspondiente no se rige directamente por el marco establecido por el PNAIN 2013-2016 como sí lo hacen otras CCAA. 
Esto no supone que el plan castellano-leonés se distancie del logro de la IA. Al contrario, esta sigue siendo su finalidad, si bien toma como referentes directos los Objetivos de Desarrollo Sostenible de la Agenda 2030. De igual modo, como ocurre en el caso cántabro, la lucha contra la exclusión social no se identifica únicamente como objeto de los servicios sociales, sino que se incluyen a todos los departamentos de la administración regional capaces de facilitar y promover la plena integración de las personas en situación o riesgo de exclusión. Así, el Plan Estratégico de Servicios Sociales otorga un valor clave a la coordinación interdepartamental con, por ejemplo, el ámbito sanitario, el educativo y el de la vivienda, entre otros. De ahí que, este plan estratégico huya de solaparse con otras planificaciones sectoriales y desarrolle, en consecuencia, una serie de ejes, objetivos y medidas centradas en casos en los que el número de usuarios sea significativamente elevado, actuaciones con un carácter claramente innovador (apoyadas sobre todo en nuevas formas de gobernanza y participación en redes de distinto nivel y tipo de actores) o en acciones con un elevado valor estratégico.

Este plan incluye siete ejes estratégicos diferenciados por su orientación, divididos en objetivos estratégicos y en actuaciones concretas. De estas, las destinadas al medio rural se concentran en los seis primeros y suman una veintena. En general, estas abordan aspectos temáticos como, por ejemplo, las TIC, los servicios de atención domiciliaria, asistencia social y salud. Por el contrario, las actuaciones dirigidas a colectivos concretos son escasas. Estos hechos pueden interpretarse como resultado del interés que el Plan Estratégico castellano-leonés tiene por mejorar la accesibilidad de los servicios que ofrece, especialmente vía telemática, minimizando así el desplazamiento de sus usuarios fuera de su lugar de residencia (Cuadro 6).

\subsubsection{Castilla-La Mancha}

La Estrategia contra la Pobreza y la Desigualdad Social de Castilla-La Mancha para el período 2017-2020, aunque mantiene el diseño y enfoque de la IA propia del PNAIN 2013-2016, plantea unos contenidos temáticos relativamente distintos. Estos se desarrollan a partir de la Estrategia Europa 2020 y la Agenda 2030 para el Desarrollo Sostenible de las Naciones Unidas, que tiene entre sus objetivos acabar con todas las formas de pobreza y adopta una fuerte perspectiva de género. De este modo, la Estrategia, que cuenta con la implicación de los distintos departamentos administrativos del gobierno autonómico, se configura como un elemento transversal de la política regional cuyo foco se centra en las personas y familias en situación o riesgo de exclusión social. Para ello, se proponen tres ejes estratégicos que se diferencian entre sí por la orientación de sus medidas. Así, el primero plantea acciones de carácter paliativo para luchar contra la pobreza económica. El segundo eje contiene medidas preventivas destinadas a reducir el riesgo de caer en situación de pobreza y exclusión. Y, por último, el tercero alberga todo un conjunto de acción de mejora de la eficacia de los servicios sociales, las prestaciones y la gobernanza en materia de lucha contra la pobreza y la desigualdad social. Nos encontramos de este modo ante un conjunto diverso de medidas contra la exclusión social rural al plantear acciones planificadas, coordinadas entre sí y abiertas a su integración con programas específicos de evidente carácter territorial-rural, como es el caso de los Programas de Desarrollo Rural (PDR) (Cuadro 7).

\subsubsection{Comunidad Valenciana}

El Plan Valenciano de Inclusión y Cohesión Social (PVICS) (2017-2022) establece un modelo específico de gobernanza en la política social, tomando una perspectiva integral y transversal, vinculada con los distintos actores sociales implicados y el territorio. El plan se desarrolla a través de tres ejes: i) la promoción de la autonomía personal y la inclusión social a través del trabajo digno y de calidad, las prestaciones sociales y el acceso universal a los servicios públicos; ii) la cohesión social en el que se tienen en cuenta el ámbito relacional y comunitario; y iii) la equidad territorial y el espacio público.

De estos tres ejes sobresale, acorde con nuestra hipótesis de trabajo, el último de ellos al centrarse en la equidad territorial y, por tanto, pretender reducir las desigualdades existentes como consecuencia del lugar de residencia. Por tanto, las políticas públicas deben, según este plan, enfocarse en salvar esta discriminación y las diferencias derivadas en términos de dotación de recursos, y plantear la creación de programas especializados para el territorio, el entorno y la vecindad. 
Cuadro 6. Actuaciones destinadas a las zonas rurales en el Plan Estratégico de los Servicios Sociales de Castilla y León (2017-2021)

\begin{tabular}{|c|c|c|c|}
\hline Eje estratégico & Objetivo estratégico & Actuación & Tema \\
\hline 1 & 1.5 & 1.5 .4 & Organización funcional \\
\hline \multirow{4}{*}{2} & 2.1 & 2.1 .4 & Mayores \\
\hline & \multirow{3}{*}{2.4} & 2.4 .1 & Seguimiento y evaluación \\
\hline & & 2.4 .2 & Servicios Sociales \\
\hline & & 2.4 .6 & TIC \\
\hline \multirow{4}{*}{3} & 3.2 & 3.2 .1 & TIC \\
\hline & \multirow{3}{*}{3.3} & 3.3.1 & Salud/TIC \\
\hline & & 3.3 .2 & Salud/TIC \\
\hline & & 3.2 .4 & TIC \\
\hline \multirow{3}{*}{4} & 4.1 & 4.1 .3 & Asistencia domiciliaria \\
\hline & 4.2 & 4.2 .4 & Seguimiento y evaluación \\
\hline & 4.3 & 4.3 .2 & Asistencia domiciliaria \\
\hline \multirow{5}{*}{5} & \multirow[t]{2}{*}{5.1} & 5.1 .5 & $\begin{array}{l}\text { Acceso a servicios y presta- } \\
\text { ciones }\end{array}$ \\
\hline & & 5.1 .6 & TIC \\
\hline & \multirow{3}{*}{5.3} & 5.3 .2 & Empleo \\
\hline & & 5.3 .3 & Servicios Sociales \\
\hline & & 5.3 .4 & Organización funcional \\
\hline \multirow{3}{*}{6} & 6.1 & 6.1 .2 & Empleo \\
\hline & \multirow{2}{*}{6.3} & 6.3 .2 & Diagnóstico territorial \\
\hline & & 6.3 .3 & Diagnóstico territorial \\
\hline
\end{tabular}

Fuente: Junta de Castilla y León, 2017.

Cuadro 7. Actuaciones destinadas a las zonas rurales en la Estrategia contra la pobreza y la desigualdad social de Castilla-La Mancha (2017-2020)

\begin{tabular}{|c|c|c|c|}
\hline Eje estratégico & Objetivo operativo & Actuación & Tema \\
\hline \multirow{2}{*}{1} & \multirow{2}{*}{2} & 10 & Desempleo \\
\hline & & 11 & Desarrollo local \\
\hline \multirow{3}{*}{2} & 1 & 14 & Planificación integral \\
\hline & 2 & 15 & Educación / formación \\
\hline & 4 & 25 & Empleo \\
\hline 3 & 10 & 56 & PDR-LEADER \\
\hline
\end{tabular}

Fuente: Gobierno de Castilla-La Mancha, 2017. 
Así se explica que el PVICS plantee todo un conjunto de acciones específicamente dirigidas al medio rural, con las que conseguir la recuperación de actividades y el freno a la despoblación por medio de la agricultura ecológica, el comercio de proximidad y un sistema de protección social basado en el acceso a la vivienda y el uso de las tierras abandonadas. Sin olvidar el papel clave que juega el transporte público y un sistema de movilidad que armonice los horarios con la idiosincrasia de la sociedad rural (Cuadro 8).

Cuadro 8. Actuaciones destinas a las zonas rurales en el PVICS (2017-2022)

\begin{tabular}{|c|c|c|c|c|c|}
\hline Eje & Línea estratégica & Obj. estratégico & Obj. operativo & Actuación & Tema \\
\hline \multirow{3}{*}{1 y 2} & \multirow{3}{*}{3} & \multirow{3}{*}{3} & \multirow{3}{*}{1} & 8 & Servicios sanitarios \\
\hline & & & & 5 & Fomento de la lectura \\
\hline & & & & 6 & Acceso a servicios bibliotecarios \\
\hline \multirow{15}{*}{1 y 3} & \multirow{15}{*}{4} & \multirow{15}{*}{4} & \multirow{4}{*}{1} & 4 & $\begin{array}{l}\text { Diseños de políticas públicas ajus- } \\
\text { tados a tipos de territorios }\end{array}$ \\
\hline & & & & 8 & Órganos de coordinación sectorial \\
\hline & & & & 12 & Participación ciudadana \\
\hline & & & & 13 & Mayores \\
\hline & & & \multirow{7}{*}{2} & 16 & Difusión cultural \\
\hline & & & & 17 & Accesibilidad a servicios públicos \\
\hline & & & & 18 & Fomento de la movilidad \\
\hline & & & & 19 & Oferta de entidades financieras \\
\hline & & & & 21 & Envejecimiento demográfico \\
\hline & & & & 22 & $\begin{array}{l}\text { Armonización horaria transpor- } \\
\text { te-servicios }\end{array}$ \\
\hline & & & & 31 & Mejora de las comunicaciones \\
\hline & & & \multirow{2}{*}{3} & 34 & Planificación territorial \\
\hline & & & & 42 & Vertebración y capital social \\
\hline & & & \multirow{2}{*}{5} & 77 & Solidaridad intergeneracional \\
\hline & & & & 80 & Escuelas de música \\
\hline \multirow{3}{*}{1 y 2} & \multirow{3}{*}{5} & \multirow{3}{*}{5} & \multirow{2}{*}{1} & 6 & Infancia \\
\hline & & & & 9 & Red familiar, social y comunitaria \\
\hline & & & 5 & 54 & Participación ciudadana \\
\hline \multirow{2}{*}{1 y 2} & \multirow{2}{*}{6} & \multirow{2}{*}{6} & 1 & 11 & Alfabetización digital \\
\hline & & & 5 & 30 & Emprendimiento femenino \\
\hline
\end{tabular}

Fuente: Generalitat Valenciana, 2017.

\subsubsection{Extremadura}

Al igual que el caso aragonés, la comunidad extremeña organiza su estrategia de inclusión social para 20142020 a partir del marco establecido por el Programa Operativo del FSE. De este modo, se propone una planificación que entronca con los objetivos de la Estrategia Europea 2020 y el enfoque de IA que recoge el PNAIN 2013-2016.

Estamos de nuevo ante una estructura organizada alrededor de tres ejes estratégicos, dirigidos hacia el fomento del empleo y la movilidad laboral, el logro de la inclusión social y la lucha contra la pobreza, y la 
intervención en educación, formación y capacitación profesional. Este planteamiento, al igual que ocurre en Aragón, se divide en diferentes niveles de concreción, desde los objetivos temáticos hasta las líneas de actuación. De nuevo, son estas las únicas partes de toda la estrategia en las que se diferencian tipos de territorios, restando los de carácter rural explícitamente recogidos en el ámbito del segundo y del tercer eje. De ambos, es el tercero y último el que presenta una mayor atención al medio rural (Cuadro 9), si bien con unos contenidos relativamente similares, al quedar cuatro de las seis medidas dirigidas hacia la educación y la formación.

Cuadro 9. Actuaciones destinadas a las zonas rurales en Estrategia del Programa Operativo del FSE de Extremadura (2014-2020)

\begin{tabular}{|c|c|c|c|c|c|}
\hline Eje estratégico & Obj. temático & $\begin{array}{l}\text { Prioridad de } \\
\text { inversión }\end{array}$ & Obj. específico & Actuación & Tema \\
\hline \multirow{3}{*}{2} & \multirow{3}{*}{9} & \multirow{3}{*}{3} & 1 & 7 & Mujer / Género \\
\hline & & & \multirow{2}{*}{2} & 1 & Cultura / interculturalidad \\
\hline & & & & 4 & Inmigración \\
\hline \multirow{6}{*}{3} & \multirow{6}{*}{10} & 2 & 3 & 1 & Educación / formación \\
\hline & & \multirow{3}{*}{3} & 1 & 6 & Educación / formación \\
\hline & & & 2 & 2 & Educación / formación \\
\hline & & & 4 & 1 & Acreditación profesional \\
\hline & & \multirow{2}{*}{4} & 1 & 5 & Educación / formación \\
\hline & & & 2 & 4 & Difusión de conocimientos \\
\hline
\end{tabular}

Fuente: Gobierno de Extremadura, 2014.

\subsubsection{Galicia}

La Estrategia de Inclusión Social (EIS) de Galicia 2014-2020 materializa la Ley 10/2013 de Inclusión Social gallega y desarrolla el Programa Operativo del FSE 14-20 en su Objetivo Temático 9 "Promover la inclusión social y luchar contra la pobreza y cualquier forma de discriminación". Como resultado, la perspectiva de trabajo de la EIS gallega se centra en la IA y, para aplicarla, el plan se articula en dieciséis prioridades: ocho transversales y ocho sectoriales. Las primeras evidencian un carácter preventivo con el que actuar antes de que los procesos de exclusión cobren fuerza, y focalizan sus acciones en personas, familias y territorios afectados por los efectos de la crisis demográfica y las desigualdades tanto en ámbitos urbanos (barrios degradados y asentamientos chabolistas) como rurales. Por su parte, las segundas ocho prioridades, debido a su carácter sectorial, se centran en los tres ámbitos de la IA: la activación sociolaboral, el apoyo a las rentas e ingresos, y el acceso a unos servicios de calidad, especialmente relacionados con la asistencia social, la educación, la sanidad y la vivienda.

Las dieciséis prioridades se subdividen en varias líneas de actuación, objetivos estratégicos y medidas. Entre estas últimas podemos destacar un total de veintidós específicamente dirigidas al medio rural, con las que hacer frente a la soledad y al aislamiento de parte de la población, al menor acceso a servicios básicos y a las consecuencias que llevan consigo el reducido tamaño de la población activa y unas tasas de paro elevadas y persistentes (Cuadro 10). Además, la estrategia gallega presenta la singularidad de apoyarse explícitamente en los Programas de Desarrollo Rural, al constituir estos, vías de probada eficacia en la intervención sobre los factores de vulnerabilidad tanto de personas como de territorios en situación de exclusión. 
Cuadro 10. Actuaciones destinadas a las zonas rurales en la Estrategia de Inclusión Social de Galicia (2014-2020).

\begin{tabular}{|c|c|c|c|c|}
\hline & Prioridades & Objetivos operativos & Actuaciones/Medidas & Temas \\
\hline \multirow{18}{*}{ 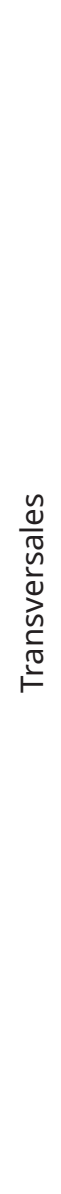 } & 2 & 1 & 2 & Menores \\
\hline & \multirow{3}{*}{3} & 1 & 4 & PDR-LEADER \\
\hline & & \multirow{2}{*}{4} & 1 & Coordinación \\
\hline & & & 3 & Coordinación \\
\hline & 4 & 1 & 1 & Comunicación \\
\hline & \multirow{11}{*}{5} & \multirow{4}{*}{1} & 1 & Acceso a servicios y prestaciones \\
\hline & & & 2 & Conciliación familiar \\
\hline & & & 3 & Educación (becas) \\
\hline & & & 4 & TIC \\
\hline & & \multirow{2}{*}{2} & 2 & TIC \\
\hline & & & 3 & Redes y calidad de vida \\
\hline & & \multirow{5}{*}{3} & 2 & Formación \\
\hline & & & 3 & Vivienda \\
\hline & & & 4 & Género \\
\hline & & & 5 & Desarrollo local \\
\hline & & & 6 & Valorización local \\
\hline & \multirow{2}{*}{8} & \multirow{2}{*}{2} & 1 & \multirow{2}{*}{ TIC } \\
\hline & & & 2 & \\
\hline \multirow{5}{*}{ 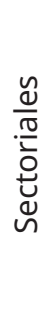 } & 1 & 2 & 2 & TIC/Empleo \\
\hline & 4 & 3 & 8 & Empleo \\
\hline & 5 & 3 & 5 & Educación \\
\hline & \multirow{2}{*}{6} & 1 & 1 & Educación \\
\hline & & 3 & 4 & Educación \\
\hline
\end{tabular}

Fuente: Xunta de Galicia, 2014.

\subsubsection{Navarra}

El Plan Estratégico de Inclusión (PEI) de Navarra 2018-2021 supone la continuación, si bien no de manera inmediata, de un primer Plan de Lucha contra la Exclusión Social autonómico (1998-2001). El tiempo transcurrido de uno a otro documento ha permitido la aprobación de una Ley foral específica sobre los Derechos a la Inclusión y a la Renta Garantizada (Ley 15/2016), que marca la estructura del actual Plan Estratégico y permite, a su vez, recoger los objetivos de la Agenda 2030 para el Desarrollo Sostenible y de la Estrategia Europea 2020 dirigidos a luchar contra la pobreza y la exclusión social a través de la IA. Para ello, el PEI de Navarra se divide en dos bloques y seis ejes estratégicos básicos: el primer bloque, con tres ejes de genéricos centrados en cuestiones sobre la protección económica y la cobertura de las necesidades básicas, la eficacia de las medidas de activación laboral para la mejora de la empleabilidad y el refuerzo de los procesos de incorporación social. El segundo bloque recoge otros tres ejes, pero con temáticas más sectoriales: la vivienda, la sanidad y la educación, sobre los que se resalta la necesidad de promover la participación social 
de la población en situación de exclusión. El fin no es otro que evitar así las situaciones de exclusión como resultado de la ausencia de relaciones sociales.

Por su parte, las medidas dirigidas expresamente al medio rural se centran en cuestiones de corte laboral, sin dejar de lado ningún ámbito temático sectorial (Cuadro 11).

Cuadro 11. Actuaciones destinadas a las zonas rurales en el Plan Estratégico de Inclusión de Navarra (2018-2021).

\begin{tabular}{|c|c|c|l|}
\hline Eje estratégico & Objetivo operativo & Actuación & \multicolumn{1}{|c|}{ Tema } \\
\hline \multirow{2}{*}{2} & \multirow{3}{*}{ C } & C7 & Empleo / Formación \\
\cline { 2 - 4 } & & C14 & Empleo \\
\cline { 2 - 4 } & \multirow{2}{*}{ F } & C19 & Empleo \\
\hline 3 & C & F2 & Integración \\
\hline 4 & B & C9 & Vivienda \\
\hline 5 & C & B5 & Sanidad/transporte \\
\hline 6 & & C5 & Educación \\
\hline
\end{tabular}

Fuente: Gobierno de Navarra, 2017.

\subsubsection{País Vasco}

Esta autonomía presenta una dilatada trayectoria al registrar ya en 1988 un Primer Plan Integral contra la Pobreza. El actual, el IV Plan Vasco de Inclusión para el período 2017-2021, se basa en las "innovaciones, tendencias, buenas prácticas y/o paradigmas conceptuales" (Gobierno Vasco, 2018, p.40) que permitan el paso de un enfoque apoyado en la IA del PNAIN 2013-2016, a otro caracterizado por la activación inclusiva. Este nuevo paradigma supone una mayor atención a la naturaleza multicasual de la exclusión social, reconociendo la importancia del empleo remunerado para el logro de la inclusión, pero también que este por sí solo ni en sí mismo es suficiente para conseguir esta. Otras diferencias propias de este IV Plan radican en su capacidad para contar con programas individualizados contra la exclusión, de priorizar la prevención, de consolidar la acción derivada del voluntariado, y del apoyo antes, durante y después del procedimiento de inclusión social.

La estructura del IV Plan Vasco de Inclusión presenta el diseño habitual, con tres ejes estratégicos subdivididos en varios objetivos $y$, estos, en distintas metas que a la vez se subdividen en actuaciones. De estas últimas, ocho son las que hemos considerado como aplicables explícitamente al medio rural (Cuadro 12). En realidad, este IV Plan Vasco más que proponer actuaciones concretas en este sentido, concentra sus esfuerzos para la inclusión social en el medio rural en la realización de estudios que permitan conocer cuáles son los colectivos vulnerables y cuál es el efecto de las políticas sociales aplicadas.

Cuadro 12. Actuaciones destinadas a las zonas rurales en el IV Plan Vasco de Inclusión (2017-2021).

\begin{tabular}{|c|c|c|l|}
\hline \multirow{2}{*}{ Eje estratégico } & Objetivo operativo & Actuación & \multicolumn{1}{|c|}{ Tema } \\
\hline \multirow{2}{*}{2} & \multirow{2}{*}{21} & 37 & Inclusión territorial \\
\cline { 2 - 4 } & & 38 & Inclusión territorial \\
\cline { 2 - 4 } & 22 & 39 & Inclusión territorial \\
\cline { 2 - 4 } & 23 & 92 & Pobreza energética \\
\hline \multirow{2}{*}{3} & 27 & 93 & Educación \\
\hline \multirow{2}{*}{3} & 28 & 107 & Articulación y coordinación \\
\cline { 2 - 4 } & 34 & 112 & Articulación y coordinación \\
\cline { 2 - 4 } & & 143 & Mujer / Género \\
\hline
\end{tabular}

Fuente: Gobierno Vasco, 2018. 


\subsection{Comparativa autonómica}

En general, en cada una de las líneas, prioridades o ejes estratégicos incluidos en los planes analizados encontramos habitualmente una subdivisión en objetivos y, estos a su vez, en actuaciones o medidas. En cuanto a los objetivos, independientemente de su denominación específica, ninguno se destina de forma concreta al medio rural, sino que adoptan una perspectiva genérica sin ofrecer detalles del tipo de territorio al que aplicarse. De ahí que, la mención particular al medio rural se registre siempre en el ámbito de las medidas o acciones, último eslabón jerárquico. En total, se han identificado 117 actuaciones distribuidas de forma heterogénea entre los distintos planes autonómicos, siendo el PVICS (relativo a una Comunidad Autónoma "urbana") donde se encuentra el mayor número de medidas y, por el contrario, en los planes de Andalucía, Madrid y de Cataluña, el mínimo (Cuadro 13).

Cuadro 13. Número de actuaciones destinadas al medio rural de cada plan autonómico e importancia respecto al total de actuaciones rurales.

\begin{tabular}{|c|c|c|c|c|}
\hline $\begin{array}{l}\text { Comunidad } \\
\text { Autónoma }\end{array}$ & $\begin{array}{c}\text { Carácter territorial } \\
\text { (criterio OCDE) }\end{array}$ & $\begin{array}{c}\text { Actuaciones rurales } \\
\text { (datos absolutos / } \\
\text { relativos) }\end{array}$ & $\begin{array}{c}\text { Actuaciones totales } \\
\text { por CCAA }\end{array}$ & $\begin{array}{c}\% \text { actuaciones rurales } \\
\text { sobre total actuaciones } \\
\text { autonómicas }\end{array}$ \\
\hline Com. Valenciana & Urbano & $23(19,66 \%)$ & 486 & $4,73 \%$ \\
\hline Galicia & Rural & $22(18,80 \%)$ & 324 & $6,79 \%$ \\
\hline Castilla y León & Rural & $20(17,09 \%)$ & 101 & $19,80 \%$ \\
\hline Cantabria & Rural & $10(8,55 \%)$ & 263 & $3,80 \%$ \\
\hline Extremadura & Rural & $9(7,69 \%)$ & 48 & $18,75 \%$ \\
\hline País Vasco & Urbano & $8(6,84 \%)$ & 146 & $5,48 \%$ \\
\hline Com. F. de Navarra & Rural & $7(5,98 \%)$ & 161 & $4,35 \%$ \\
\hline P. de Asturias & Rural & $6(5,13 \%)$ & 259 & $2,32 \%$ \\
\hline Castilla-La Macha & Rural & $6(5,13 \%)$ & 58 & $10,34 \%$ \\
\hline Aragón & Rural & $6(5,13 \%)$ & 24 & $25,00 \%$ \\
\hline Andalucía & Rural & $0(0,00 \%)$ & 137 & $0,00 \%$ \\
\hline Cataluña & Urbano & $0(0,00 \%)$ & 164 & $0,00 \%$ \\
\hline Com. de Madrid & Urbano & $0(0,00 \%)$ & 135 & $0,00 \%$ \\
\hline Total & - & $117(100,00 \%)$ & 2.234 & $5,2 \%$ \\
\hline
\end{tabular}

Fuente: Elaboración propia a partir de los planes de inclusión analizados en el texto.

Del total de las actuaciones identificadas, $86(73,5 \%)$ se hallan en CCAA predominantemente rurales, mientras que solo $31(26,5 \%)$ son actuaciones relativas a planes de CCAA consideradas como predominantemente urbanas (y en concreto, la mayor parte a una única autonomía, la Comunidad Valenciana). Las 86 medidas asociadas al medio rural no se reparten de manera homogénea entre las autonomías que las contemplan, sino que aproximadamente la mitad (42 de ellas) se concentran en dos, Galicia y Castilla y León (22 en el primer caso, 20 en el segundo). Las restantes seis CCAA caracterizadas de rurales registran unas cantidades que apenas varían entre sí en cuatro unidades, pasando de seis actuaciones en el menor de los casos (Aragón, Castilla-La Mancha y Asturias) a siete (Navarra), nueve (Extremadura) y diez (Cantabria).

Este menor número de medidas no quiere decir que estemos ante autonomías en donde el interés por atender el carácter rural de la exclusión social sea reducido, ya que precisamente nos encontramos con 
CCAA eminentemente rurales como Aragón y Castilla-La Mancha, por ejemplo. El motivo es otro. Cuantitativamente son pocas las medidas desarrolladas en estos casos porque, en general para el conjunto autonómico, el número de actuaciones propuestas para el logro de la inclusión social también es reducido. En todo caso, debemos recordar que no valoramos si las medidas planteadas son más o menos eficaces, sino si la planificación autonómica es capaz de reconocer la diversidad de espacios y situaciones en las que los procesos de exclusión tienen lugar, ya que aquellos que se desarrollan en zonas rurales son distintos de los urbanos y, por tanto, requieren de un planteamiento particular.

De ahí que resulte más interesante atender al peso que las medidas dirigidas explícitamente al medio rural alcanzan por CCAA. Desde esta perspectiva, el panorama recogido a partir del análisis realizado evidencia una situación autonómica dispar. Por un lado, encontramos autonomías "rurales" en donde las actuaciones para hacer frente a los problemas relacionados con la exclusión social del medio rural quedan por debajo de la media nacional (5,2\%) (casos de Asturias, Navarra y Cantabria). Y, por otro lado, CCAA en donde los porcentajes recogidos doblan el valor medio del conjunto estatal (Castilla-La Mancha, Extremadura, Castilla León y Aragón).

Esta diversidad de resultados evidencia cierta paradoja, pues demuestran la existencia de CCAA "rurales" con una atención específica por el medio rural inferior a la registrada por autonomías con un perfil relativamente más urbano (Comunidad Valenciana y País Vasco). Luego, el carácter territorial con el que hemos clasificado las CCAA no predetermina la mayor o menor cantidad de actuaciones dirigidas a tratar los procesos de exclusión social presentes en los espacios rurales.

Sin embargo, la anterior afirmación puede ser matizada según las características predominantemente rurales o urbanas de las CCAA. En relación a las primeras, cuanto menor es el número de medidas generales registrado por el plan autonómico en cuestión, mayor peso alcanzan las dirigidas concretamente a los territorios rurales y, por tanto, más atención relativa reciben estos. En cuanto a las segundas, la atención concreta que reciben los espacios rurales en las políticas sociales dirigidas a la lucha contra la exclusión social resulta, en el mejor de los casos, testimonial.

En todo caso, los resultados evidencian el planteamiento genérico que predomina a la hora de diseñar y organizar actuaciones para confrontar los procesos y las situaciones de exclusión, y por tanto el escaso valor otorgado al carácter territorial de dicho fenómeno. Autores como Commins, P. (2004), Bertolini, P., et al. (2008), Bock, B., et al. (2015) y Bernard, J., et al. (2019) señalan como principales motivos de esta situación la invisibilidad social, espacial y mediática que los fenómenos de pobreza y exclusión social alcanzan en los territorios rurales, así como el relativamente escaso rédito político que supone trabajar a favor de la inclusión social en estos. Un hecho especialmente delicado en un contexto político internacional en el que los postulados nacionalistas excluyentes y de extrema derecha aumentan y se nutren, especialmente, de zonas rurales y desfavorecidas (Rodríguez-Pose, A., 2017).

Por su parte, el análisis temático de las 117 medidas específicamente rurales localizadas en los planes analizados (Cuadro 14), evidencia cierto predominio de aspectos vinculados con el desarrollo territorial, la planificación y la elaboración de diagnósticos socioeconómicos (así ocurre en un 18,80\% de los casos). Este resultado subraya la estrecha relación que cada vez más se da a la identificación y resolución de problemas y necesidades sociales relativos a colectivos concretos, con el bienestar y la calidad de vida capaz que es capaz de ofrecer en su conjunto, el territorio particular en el que dichas dificultades son una realidad. Así, los problemas de acceso a vivienda o empleo remunerado que afectan a mujeres, jóvenes, personas con discapacidad e inmigrantes en el medio rural, por ejemplo, pueden de igual modo afectar a otros perfiles sociodemográficos de igual modo. La tensión resultante afecta no solo al crecimiento o desarrollo económico, sino también altera el potencial social y cultural de la comunidad, que, a su vez y a largo plazo, puede menoscabar la capacidad de esta para actuar y regenerarse. Luego, la salida constante de población, con independencia de sus circunstancias individuales, puede llegar a provocar una pérdida de poder socioeconómico y político territorial cuando la pérdida de habitantes supone la ruptura de las relaciones y recursos internos y externos de la población local (Bock, B., 2016).

A continuación, y con un peso similar, destacan las medidas dirigidas a la mejora de las capacidades y rasgos de empleabilidad de la población en general, a través del fomento de acciones relacionadas con el ámbito de la educación y de la formación (actuaciones que suponen el 17,09\% del total de las desarrolladas). 
Cuadro 14. Temáticas frecuentes en las actuaciones rurales sobre el total en las CCAA predominantemente rurales.

\begin{tabular}{|c|c|c|c|c|}
\hline Orden & Temática & $\mathrm{N}^{\circ}$ de actuaciones & $\%$ total & $\%$ acumulado \\
\hline 1 & Medidas territoriales, de desarrollo y planificación (*) & 22 & 18,80 & 18,80 \\
\hline 2 & Medidas educativas y/o formativas & 20 & 17,09 & 35,90 \\
\hline 3 & Medidas colectivos más vulnerables & 17 & 14,53 & 50,43 \\
\hline 4 & $\begin{array}{l}\text { Medidas de fomento del empleo y/o disminución del } \\
\text { desempleo }\end{array}$ & 15 & 12,82 & 63,25 \\
\hline 5 & Medidas sociedad de la información - TIC & 9 & 7,69 & 70,94 \\
\hline 6 & Medidas acceso a servicios y/o prestaciones & 8 & 6,84 & 77,78 \\
\hline 7 & Medidas sanitarias (*) & 5 & 4,27 & 82,05 \\
\hline 8 & Medidas de incidencia familiar y sociocomunitaria & 5 & 4,27 & 86,32 \\
\hline 9 & $\begin{array}{l}\text { Medidas de articulación y coordinación entre } \\
\text { administraciones }\end{array}$ & 4 & 3,42 & 89,74 \\
\hline 10 & Medidas de asistencia social y/o servicios sociales $\left(^{*}\right)$ & 4 & 3,42 & 93,16 \\
\hline 11 & Medidas de participación, seguimiento y evaluación & 4 & 3,42 & 96,58 \\
\hline 12 & Medidas de viviendas (*) & 4 & 3,42 & 100,00 \\
\hline \multicolumn{2}{|r|}{ Total } & 117 & 100,00 & 100,00 \\
\hline
\end{tabular}

Fuente: Elaboración propia a partir de los planes de inclusión analizados en el texto. Nota $\left(^{*}\right)$ : temáticas no previstas en los objetivos estratégicos del PNAIN 2013-2016.

Este planteamiento conecta claramente con el enfoque de las capacidades defendido por Sen, A. (2000), en la medida que el uso de bienes y servicios no es lo importante, sino que su valor se encuentra en la utilización que las personas puedan darles a estos para resolver los problemas que les afectan. Lógicamente, esta utilización está relacionada de forma directa con el conocimiento y dominio de los recursos disponibles. Ahora bien, no debemos caer en el error de sobrevalorar la responsabilidad y los esfuerzos que la población en riesgo o situación de exclusión social debe realizar. Al contrario, junto a ellos el papel del estado debe avanzar y adoptar más bien un rol de coordinador, gerente o facilitador en lugar de aparecer únicamente como proveedor directo de bienes y servicios (Shucksmith, M., 2010). Luego, desde las políticas públicas se debe promover el desarrollo de capacidades entre la población a través de, como es el caso de las actuaciones aquí identificadas, un reconocimiento explícito por la adquisición de capacidades dirigidas al crecimiento personal y profesional.

No obstante, las acciones encaminadas a colectivos vulnerables específicos como los constituidos por mujeres e inmigrantes, sobre todo, aunque también con atención a personas con algún tipo de discapacidad, mayores y población infantil, registran de igual modo un peso destacado, con un $14,53 \%$ sobre el total. Estos colectivos entran, de algún modo, en el paquete de actuaciones habituales a favor de la inclusión social de personas y/o familias concretas, en tanto en cuanto todos ellos se visibilizan con facilidad y frecuencia (incluso alguno de ellos, como el de mayores, es el más representativo de los habitantes del medio rural). Sin embargo, otros colectivos como las personas reclusas o exreclusas, personas con problemas de adicción, con problemas de discriminación por orientación sexual o identidad de género, por cuestiones de raza o etnia, desempleados estructurales, personas sin hogar, etc., no son recogidos de modo alguno en ninguna de los planes o estrategias analizados, muy probablemente porque se trata de perfiles de población que "escapan" a las estadísticas y a los estudios tradicionales. Este hecho conlleva la existencia de un vacío en la atención específica que puedan recibir estas personas, en la medida que no se puede atender lo que no 
se conoce. De ahí que, solo el reconocimiento de la diversidad sociocultural y demográfica de los territorios rurales, permite diseñar actuaciones que atiendan las distintas circunstancias y grupos presentes en los mismos, en un aspecto tan importante para el bienestar de la población rural como es el de su inclusión social y territorial. Luego, si no se (re)conoce la sociedad rural de forma desagregada, los diagnósticos realizados con los que organizar las soluciones oportunas se caracterizarán por su generalidad e inexactitud, conllevando consecuentemente a la ineficiencia e insostenibilidad de las posibles soluciones a implementar (Escribano, J. y del Romero, L., 2019).

Estos tres conjuntos temáticos (desarrollo territorial, planificación y diagnóstico socioeconómico; mejora de las capacidades y rasgos de empleabilidad; y acciones encaminadas a colectivos vulnerables específicos) suponen la mitad de los contenidos recogidos en los planes de lucha contra la exclusión social analizados. La otra mitad se reparte, en cambio, entre un abanico de temas más amplio. De estos, nueve en total, destaca el vinculado con las medidas propuestas para el fomento del empleo y lucha contra el desempleo, al lograr un peso relativo de casi un 13\% sobre las 117 acciones enumeradas. En cierto modo, el emplazamiento de la cuestión laboral en cuarta posición se entiende si tenemos en cuenta que el problema del empleo se relaciona más con el tipo de trabajo que con la ausencia del mismo. Se trata, más bien, de dar respuesta a situaciones laborales caracterizadas por una escasa remuneración, temporalidad, parcialidad, e incluso, sumergidas o no declaradas. Sin duda, toda una serie de rasgos predominantes en los sectores de actividad habituales en los espacios rurales (agricultura, construcción, servicios a la población, etc.) (Escribano, J. y Vercher, N., 2018).

Las ocho agrupaciones temáticas restantes presentan una reiteración menor, si bien en ningún caso puede decirse que se trate de contenidos aislados, ya que como mínimo aparecen repetidos en cuatro ocasiones, y siempre en más de una Comunidad Autónoma. Entre estos temas, eso sí, menos habituales, se recogen medidas tan diversas como las dirigidas a la extensión de las TIC como vía para reducir la exclusión, la mejora en acceso físico a diversos servicios y prestaciones sociales (como la asistencia domiciliaria, la oferta cultural, etc.), el aumento del bienestar sanitario de la población, la apuesta por una mayor vertebración y articulación social a través de la recuperación de redes familiares, solidarias y de conciliación, y medidas enfocadas a la coordinación y trabajo administrativo en red, a la lucha contra la pobreza energética, al desarrollo de procesos evaluativos y, por último, al incremento y mejora del parque de vivienda (con acciones dirigidas tanto a facilitar el acceso a esta como de mejora o rehabilitación de los inmuebles).

Lógicamente, el desarrollo posterior de los planes autonómicos respecto al PNAIN 2013-2016, el carácter no vinculante de este y, sobre todo, su relativo desfase temporal supone que las temáticas recogidas por la planificación autonómica no solo sean relativamente más diversas a la hora de aproximarse al logro de la inclusión social, sino que además se ajusten comparativamente mejor a las necesidades recientes experimentadas por la población del medio rural (pobreza energética, exclusión financiera, etc.). Este ajuste o adecuación "espacial" evidencia el progresivo reconocimiento de que políticas sociales deben plantearse desde una perspectiva territorial (como ocurre por ejemplo, en el caso de la Comunidad Valenciana), o al menos recoger dicho enfoque en el desarrollo de sus medidas si se pretende lograr que estas sean no solo eficaces (responda a unos objetivos concretos), sino relevantes (atiendan a las necesidades de la población rural) en su propósito de lucha contra la exclusión y, por tanto, desarrollo inclusivo. En este sentido, son varias las CCAA que avanzan aún más en dicho planteamiento y reconocen que el logro de la inclusión social no depende o no debe vehicularse únicamente a través de planes o estrategias de lucha contra la exclusión procedente de un área concreta como es la de servicios sociales, sino que, si el problema es multidimensional, la solución debe proceder de la coordinación y trabajo conjunto de diversos ámbitos, como el educación o el sanitario (por ejemplo, este sería el caso de las CCAA de Cantabria, Castilla León y Castilla-la Mancha).

\section{CONCLUSIONES}

Uno de los factores clave de los procesos de exclusión social y las situaciones de pobreza en el medio rural reside en la disponibilidad y acceso a servicios (Bertolini, P., et al., 2008). Entre estos cobran especial relevancia los servicios que articulan el Estado de Bienestar y, a su vez, por las características intrínsecas 
del fenómeno, los relativos al ámbito social (Servicios Sociales Generales), principales proveedores de la política social orientada de forma expresa y específica a la prevención y atención de los riesgos de pobreza y exclusión. Además, en contextos de territorios afectados por procesos de estigmatización, como son los rurales, la retirada de servicios públicos, especialmente aquellos ligados al Estado de Bienestar, incrementa las dificultades económicas y de degradación ecológica y comunitaria, tanto material como simbólicamente (Bock, B., et al., 2015). De ahí que, para el medio rural, la provisión de servicios sociales y otras herramientas e instrumentos de política social puede actuar directamente como elemento de bienestar social de la población rural.

En España, las políticas sociales en general, y las orientadas a enfrentar la pobreza y exclusión social en particular, son competencia tanto del gobierno central como de los gobiernos autonómicos debido a la compleja estructura descentralizada del Estado. Así, por ejemplo, la configuración general del sistema de pensiones o el fiscal, entre otros, son competencias exclusivas del Gobierno de España, si bien la regulación específica y desarrollo de las políticas sociales que materializan dichas directrices generales son competencia de las CCAA. Es decir, bajo el marco común establecido por el Estado, cada región puede estructurar su política social particular.

Sin embargo, esta competencia para diseñar y organizar la política social de manera territorializada no se ve correspondida, en general, con una atención completa y específica sobre la realidad diferenciada que configura los espacios rurales de las CCAA. En consecuencia, las políticas de inclusión social dirigidas específicamente a estos espacios, o con cierta capacidad para actuar de manera particular sobre ellos según sus demandas y necesidades, son más bien una excepción. En los diez planes autonómicos analizados, la atención al medio rural se encuentra únicamente en las actuaciones, último eslabón jerárquico en el que se organizan las políticas de inclusión social. No hay ni ejes estratégicos ni objetivos de tipo alguno que aborden con concreción el problema de la exclusión social en medio rural. Sí que es cierto que aquellas autonomías predominantemente rurales (entendido este rasgo como sinónimo de una densidad demográfica inferior a 150 habitantes por kilómetro cuadrado), presentan en conjunto un mayor número de actuaciones que las CCAA relativamente urbanas.

Esto no quiere decir que estas últimas no hayan desarrollado planteamientos que aboguen por diferenciar espacios con problemas particulares de exclusión social y/o económica. Sin embargo, el hecho de que apenas se reconozca en estas autonomías la idiosincrasia de los territorios rurales, cuya pobreza o exclusión social dista de ser idéntica a la urbana, cuestiona que las medidas adoptadas sean ya no eficaces o eficientes, sino como mínimo relevantes. El motivo es sencillo de entender, puesto que no es lo mismo ofrecer una actuación destinada específicamente al espacio rural que contar con un conjunto de actuaciones generalistas que no delimitan el tipo de territorio al que se van a destinar (Commins, P., 2004). Esto puede resultar una omisión de la problemática rural, ya que las actuaciones pueden acabar aplicándose en los espacios donde se concentra mayor cantidad de población y más demanda, y por tanto donde resulta más rentable económica y políticamente su desarrollo (Escribano, J. y Valero, D. E., 2018).

Nos encontramos en un momento en el que muchos de los territorios rurales españoles, especialmente aquellos despoblados y empobrecidos económica y socialmente, precisan de acciones urgentes capaces de atender sus legítimas reivindicaciones. Es decir, lograr que su población pueda disfrutar de una buena calidad de vida sin necesidad de abandonar su espacio de vida. Sin embargo, pese a la multitud de documentos, informes, estrategias, planes y agendas desde muy distintas organizaciones que diagnostican una y otra vez el medio rural, el cambio que anhela su población sigue sin producirse. La situación de bloqueo, indefinición y falta de voluntad política relegan en la sociedad civil, en el talento y compromiso de sus gentes, la posibilidad de permanencia en los pueblos. Pero esta no solo se agota, sino que en muchos casos se hastía al ver que muchas de las políticas e instrumentos con capacidad para resolver sus problemas ya existen, que no cabe idear ni generar nada nuevo, tan solo deben aplicarse de un modo diferenciado, abandonando su carácter universalista y uniforme, y enmarcándose en una perspectiva de trabajo territorial e integradora.

Por consiguiente, más allá de la actualización de la comparativa aquí realizada incorporando los planes de inclusión aparecidos desde la fecha en la que finaliza nuestro trabajo, los siguientes pasos a dar en el estudio de esta temática deberían consolidar el interés por el análisis del bienestar rural desde un enfoque 
de trabajo dinámico y multidimensional, capaz de incorporar a su vez las relaciones de poder, los sistemas de asignación de recursos y de toma de decisiones, temas aun marginales tanto en la academia como en el ámbito de las políticas públicas. De hecho, las iniciativas sobre reforma del Estado de Bienestar, de los mercados laborales y de los instrumentos y vías de lucha contra la exclusión social y la pobreza, continúan desarrollándose básicamente como respuesta a la crisis socioeconómica y financiera de la ciudad y en la ciudad. Esta es una omisión que cabe subsanar si pretendemos lograr la plena inclusión de la sociedad rural, para lo que resulta clave superar las representaciones urbanas sobre cómo abordar el problema de la exclusión social en este tipo de territorios, y buscar enfoques que tomen en serio la geografía y el contexto organizacional local.

\section{REFERENCIAS BIBLIOGRÁFICAS}

Aguilar, M., Alfama, E., Arriba, A., Carrasco, C., Casado, D., Casas, F., ... Montserrat, J. (2014). Estado de bienestar en España: transformaciones y tendencias de cambio en el marco de la Unión Europea. En Fundación FOESSA (Ed.). VII Informe sobre exclusión y desarrollo social en España 2014 (pp. 300-393). Madrid: Fundación FOESSA y Cáritas Española Editores. Recuperado el 10 de noviembre de 2019 de https://www.foessa2014.es/informe/detalle_capitulo. php?id_capitulo=5

Bernard, J., Contzen, S., Decker, A. y Shucksmith, M. (2019). Poverty and social exclusión in diversified rural contexts. Sociologia Ruralis, 59 (3), 353-368. doi: https://doi.org/10.1111/soru.12260

Bertolini, P., Montanari, M. y Peragine, V. (2008). Poverty and Social Exclusion in Rural Areas. Bruselas: Comisión Europea.

Bock, B. (2016). Rural marginalisation and the role of social innovation; a turn towards nexogenous development and rural reconnection. Sociologia Ruralis, 56 (4), 552-573. doi: https://doi.org/10.1111/soru.12119

Bock, B., Kovacs, K. y Shucksmith, M. (2015). Changing social characteristics, patterns of inequality and exclusion. En A. K. Copus y P. De Lima (Eds.) Territorial cohesion in rural Europe (pp. 193-211). Abingdon: Routledge.

Boilineau, E. y Bonerandi-Richard, E. (2014). La pauvreté en Europe: une aproche géographique. Rennes: Presses Universitaries de Rennes. doi: https://doi.org/10.4000/books.pur.34518

Cabero, V., Trejo, Ma . C. y Fernández, V. (2010). Pobreza y exclusión social en el ámbito rural. Debates fundamentales en el marco de la inclusión social en España 8, 29-44.

Camarero, L. A. (1993). Del éxodo rural y del éxodo urbano. Ocaso y renacimiento de los asentamientos rurales en España. Madrid: Serie Estudios.

CES (Consejo Económico y Social) (2017). Informe 01/2017 sobre Políticas públicas para combatir la pobreza en España. Madrid: CES. Recuperado el 12 de noviembre de 2019 de http://www.ces.es/documents/10180/4509980/Inf0117. pdf/042f5f55-ee64-4d18-8040-b51df3ce0e6d

CES (Consejo Económico y Social) (2018). Informe 01/2018 sobre El medio rural y su vertebración social y territorial. Madrid: CES. Recuperado el 12 de noviembre de 2019 de http://www.ces.es/documents/10180/5182488/Inf0118.pdf/6d616668-0cb8-f58c-075b-2251f05dad9f

Commins, P. (2004). Poverty and social exclusion in rural areas: characteristics, processes and research issues. Sociologia Ruralis, 44 (1), 60-75. doi: https://doi.org/10.1111/j.1467-9523.2004.00262.x

Escribano, J. (2012). Servicios educativos y sanitarios elementales en el medio rural: percepción social e influencia sobre la calidad de vida. Estudios Geográficos 73 (272), 35-61. doi: 10.3989/estgeogr.201202

Escribano, J. y del Romero, L. (2019). El papel de los espacios rurales y la cooperación urbano-rural en la articulación del territorio valenciano. En J. Farinós (Coord.), J. Farinós y E. Peiró (eds.) Informe sobre la evolución y situación territorial de la Comunitat Valenciana (pp. 133-180). Valencia: PUV.

Escribano, J. y Valero, D. E. (2018). La dimensión rural-territorial en los procesos de exclusión social. En E. Moyano (Coord.) Informe Socioeconómico de la Agricultura Familiar Española, 2018: Agricultura, desarrollo e innovación en los territorios rurales (pp. 92-97). Madrid: Fundación de Estudios Rurales. Recuperado de: http://fademur.es/fademur/la-dimension-rural-territorial-en-los-procesos-de-exclusion-social/

Escribano, J. y Vercher, N. (2018). Jóvenes y medio rural: ¿un binomio hacia la exclusión? En V. Paül, R. C. Lois, J. M. Trillo y F. Haslam (eds.) Infinite rural systems in a finite planet: bridging gaps towards sustainability (pp. 387-394). Santiago: Cursos e Congresos. Universidad de Santiago de Compostela Publicatións. 
Escribano, J., Serrano, J. J., y Martínez, P. (2019). Análisis del riesgo de exclusión social en el medio rural: el índice Z como solución 'lowcost' a la falta de indicadores sintéticos municipales. Cuadernos Geográficos, 58 (3), pp. 103-124. doi: http://dx.doi.org/10.30827/cuadgeo.v58i3.8636

Esparcia, J. (2010). El potencial del 'análisis de contenidos' como metodología para la caracterización de modelos conceptuales-relacionales del desarrollo rural en España. En F. Leco (Ed.) Actas del XV Coloquio de Geografía Rural: territorio, paisaje y patrimonio rural (pp. 87-101). Cáceres: Universidad de Extremadura. Recuperado el 12 de noviembre de 2019 de https://www.uv.es/javier/index_archivos/Esparcia-An\%E1lisis_de_contenidos-Modelos_conceptuales_de_ desarrollo_rural_en_Espa\%F1a-Coloquio_Geograf\%EDa_Rural-C\%E1ceres-2010.pdf

Estivill, J. (2003). Panorama de la lucha contra la exclusión social. Conceptos y estrategias. Lisboa: Oficina Internacional del Trabajo. Recuperado el 12 de noviembre de 2019 dehttp://www.derechoshumanos.unlp.edu.ar/assets/files/documentos/panorama-de-la-lucha-contra-la-exclusion-social.pdf

Farrell, G., Thirion, S. y Brunet, B. (2000). Lucha contra la exclusión social en el medio rural. Innovación en el medio rural. Cuaderno de la Innovación. Observatorio europeo LEADER 8, 1-53.

Furuseth, O. (1998). Service provision and social deprivation. En B. Ilbery (Ed.) The geography of rural change (pp. 233-256). Londres: Longman.

Goerlich, F. J., Reig, E. y Cantarino, I. (2016). Construcción de una tipología rural/urbana para los municipios españoles. Journal of Regional Research, 35, 151-173. Recuperado el 12 de noviembre de 2019 de http://hdl.handle. net/10550/58323

Mathieu, N. (1997). Les enjeux de l'approche géographique de l'exclusion sociale, Économie rurale 242, 21-27. Recuperado el 12 de noviembre de 2019 de https://www.persee.fr/doc/ecoru_0013-0559_1997_num_242_1_4894. doi: https:// doi.org/10.3406/ecoru.1997.4894

MEPSYD (Ministerio de Educación, Política Social y Deporte) (2009). Los planes de inclusión social en las Comunidades Autónomas y en las Corporaciones Locales. Madrid: Secretaría General Técnica. Centro de Publicaciones. Ministerio de Educación, Política Social y Deporte. Recuperado el 12 de noviembre de 2019 de https://sede.educacion.gob.es/ publiventa/descarga.action?f_codigo_agc=12518_19

Milbourne, P. (2010). Scaling and spacing welfare reform: making sense of welfare in rural places. En P. Milbourne (Ed.) Welfare reform in rural places. Comparative perspectives (pp. 1-17). Bingley: Emerald. doi: https://doi.org/10.1108/ S1057-1922(2010)0000015003

Paniagua, A. y Hoggart, K. (2002). Lo rural, ¿hechos, discursos o representaciones? Una perspectiva geográfica de un debate clásico. Revista Información Comercial Española (ICE) 803, 61-71. Recuperado el 12 de noviembre de 2019 de https://www.researchgate.net/publication/28059029_Lo_rural_hechos_discursos_o_representaciones_una_perspectiva_geografica_de_un_debate_clasico

Rodríguez-Pose, A. (2017). The revenge of the places that don't matter (and what to do about it). Cambridge Journal of Regions, Economy and Society, 11 (1), 189-209. doi: 10.1093/cjres/rsx024.

Sen, A. (2000). Desarrollo y libertad. Barcelona: Planeta.

Shucksmith, M. (2010). Disintegrated rural development? Neo-endogenous rural development, planning and place-shaping in diffused power contexts. Sociologia Ruralis, 50 (1), 1-14. doi: https://doi.org/10.1111/j.1467-9523.2009.00497.x

Valero, D. E., Escribano, J. y Vercher, N. (2016). Social policies addressing social exclusion in rural areas of Spain and Portugal: the main post-crisis transformational trends. Sociologia e Politiche Sociali, 19 (3), 83-101. doi: 10.3280/ SP2016-003006

\section{REFERENCIAS NORMATIVAS}

Comunidad de Madrid (2016). Estrategia de inclusión social de la Comunidad de Madrid 2016-2021. Madrid: Comunidad de Madrid. Consejería de Políticas Sociales y Familia. Recuperado el 12 de noviembre de 2019 de http://www.madrid. org/es/transparencia/sites/default/files/plan/document/865_655_estrategia_de_inclusion_social_cm0_0.pdf

Generalitat de Catalunya (2015). Pla d'acció per a la lluita contra la pobresa i per a la inclusió social a Catalunya $2015-2016$. Barcelona: Generalitat de Catalunya. Departement de Treball, Afers Socials i Famílies. Recuperado el 12 de noviembre de 2019 de https://treballiaferssocials.gencat.cat/web/.content/03ambits_tematics/06pobresa_i_inclusio_social//luita_contra_pobresa/pla_pobresa.pdf. 
Generalitat Valenciana (2017). Plan Valenciano de Inclusión y Cohesión Social 2017-2022. Valencia: Generalitat Valenciana: Vicepresidència i Conselleria d'Igualtat i Polítiques Inclusives. Recuperado el 12 de noviembre de 2019 de http://www.inclusio.gva.es/documents/610754/167310235/PVICS+Castellano.pdf/30d869f5-4d01-42b6-9839$16 a 747962748$

Gobierno de Aragón (2014). Programa Operativo Fondo Social Europeo (FSE) de Aragón 2014-2020. Zaragoza: Gobierno de Aragón. Departamento de Hacienda y Administración Pública. Recuperado el 12 de noviembre de 2019 de https:// www.aragon.es/documents/20127/674325/pofsearagon20142020.pdf/e860eadd-3851-a2c9-9b04-89fbeac64bc3

Gobierno de Cantabria (2014). I Plan de Acción para la Inclusión Social en Cantabria 2014-2017. Santander: Gobierno de Cantabria. Consejería de Sanidad y Servicios Sociales. Recuperado el 12 de noviembre de 2019 de http://www.serviciossocialescantabria.org/uploads/normativa/PlanDeInclusionSocial.pdf

Gobierno de Castilla-La Mancha (2017). Estrategia contra la pobreza y la desigualdad social de Castilla-La Mancha. Toledo: Gobierno de Castilla-La Mancha. Consejería de Bienestar Social. Recuperado el 12 de noviembre de 2019 de https:// www.castillalamancha.es/sites/default/files/documentos/pdf/20171024/estrategia_contra_la_pobreza_clm_20172020.pdf

Gobierno de Extremadura (2014). Programa Operativo FSE 2014-2020 de Extremadura. Mérida: Gobierno de Extremadura. Recuperado el 12 de noviembre de 2019 de http://www.juntaex.es/filescms/ddgg002/uploaded_files/fondos_europeos/FondosEuropeos2014_2020/FEDER/Propuesta_Programa_Operativo_Fondo_Europeo_Desarrollo_Regional_Extremadura_2014-2020.pdf

Gobierno de Navarra (2017). Plan Estratégico de Inclusión de Navarra (2018-2021). Pamplona: Comunidad Foral de Navarra. Departamento de Derechos Sociales. Observatorio de la Realidad Social. Recuperado el 12 de noviembre de 2019 de https://gobiernoabierto.navarra.es/sites/default/files/plan_estrategico_de_inclusion_social_navarra_2018-2021.pdf

Gobierno Vasco (2018). IV Plan Vasco de Inclusión 2017-2021. Vitoria-Gasteiz: Gobierno Vasco. Departamento de Empleo y Asuntos Sociales. Servicio Central de Publicaciones del Gobierno Vasco. Recuperado el 12 de noviembre de 2019 de https://www.euskadi.eus/contenidos/documentacion/doc_sosa_028_iv_plan_inclusion/es_def/adjuntos/IV\%20 PLAN\%20VASCO\%20DE\%20INCLUSION.pdf

Junta de Andalucía (2014). Estrategia Regional Andaluza para la Cohesión e Inclusión Social. Intervención en Zonas Desfavorecidas. Sevilla: Junta de Andalucía, Consejería de Igualdad y Políticas Sociales. Recuperado el 12 de noviembre de 2019 de http://www.andujar.es/fileadmin/pdfs/igualdad/Estrategia_Regional_Andaluza_ERACIS2018.pd.pdf

Junta de Castilla y León (2017). Plan Estratégico de Servicios Sociales de Castilla y León 2017-2021. Valladolid: Junta de CastiIla y León. Consejería de Familia e Igualdad de Oportunidades. Recuperado el 12 de noviembre de 2019 de https:// serviciossociales.jcyl.es/web/jcyl/binarios/207/366/Plan\%20estrat\%C3\%A9gico\%20de\%20los\%20servicios\%20 sociales\%20para\%20Web.pdf?blobheader=application\%2Fpdf\%3Bcharset\%3DUTF-8\&blobheadername1=Cache-Control\&blobheadername2=Expires\&blobheadername3=Site\&blobheadervalue1=no-store\%2Cno-cache\%2Cmust-revalidate\&blobheadervalue2=0\&blobheadervalue3=JCYL_ServiciosSociales\&blobnocache=true

MSSSI (Ministerio de Sanidad, Servicios Sociales e Igualdad) (2014). Plan Nacional de Acción para la Inclusión Social del Reino de España (PNAIN) 2013-2016. Madrid: Gobierno de España. Ministerio de Sanidad, Servicios Sociales e Igualdad. Centro de publicaciones. Recuperado el 12 de noviembre de 2019 de https://www.mscbs.gob.es/ssi/familiasInfancia/inclusionSocial/docs/PlanNacionalAccionInclusionSocial_2013_2016.pdf

Principado de Asturias (2015). Plan Autonómico de Inclusión Social 2015-2017. Asturias: Gobierno del Principado de Asturias. Consejería de Bienestar Social y Vivienda. Recuperado el 12 de noviembre de 2019 de https://www.asturias.es/ Asturias/descargas/PDF_TEMAS/Asuntos\%20Sociales/plan_inclusion_social.pdf

Xunta de Galicia (2014). Estrategia de inclusión social de Galicia 2014-2020. Santiago de Compostela: Xunta de Galicia. Consellería de Política Social. Recuperado el 12 de noviembre de 2019 de https://ficheiros-web.xunta.gal/transparencia/plans/politica-social/estratexia_inclusion_social_galicia_2014_2020_cas.pdf 